\title{
Is Early Chemical Thromboprophylaxis in Patients with Solid Organ Injury a Solid Decision? \\ Short Title: "Thromboprophylaxis in Solid Organ Injuries"
}

David Skarupa, MD ${ }^{1}$, Kamil Hanna, MD², Muhammad Zeeshan, MD², Firas Madbak, MD ${ }^{1}$, Mohammad Hamidi, $\mathrm{MD}^{2}$, Zaid Haddadin, $\mathrm{MD}^{2}$, Ashley Northcutt, $\mathrm{MD}^{2}$, Lynn Gries, MD², Narong Kulvatunyou $\mathrm{MD}^{2}$, and Bellal Joseph, $\mathrm{MD}^{2}$.

${ }^{1}$ Division of Acute Care Surgery, Department of Surgery, University of Florida Health Jacksonville, Jacksonville, Florida

${ }^{2}$ Division of Trauma, Critical Care, Emergency Surgery, and Burns, Department of Surgery, College of Medicine, University of Arizona, Tucson, Arizona.

DS: david.skarupa@jax.ufl.edu

KH: kamilhanna@surgery.arizona.edu

MZ: mzeeshan@surgery.arizona.edu

FM: Firas.madbak@jax.ufl.edu

MH: hamidi@surgery.arizona.edu

ZH: Haddadinz@surgery.arizona.edu

AN: ashleynorthcutt@surgery.arizona.edu

LG: 1gries@surgery.arizona.edu

NK: nkulvatunyou@surgery.arizona.edu

BJ: bjoseph@surgery.arizona.edu

Oral presentation for the 49th Annual Meeting of Western Trauma Association, March $3^{\text {rd }}$ $-8^{\text {th }}, 2019$, Snowmass, Colorado.

There are no identifiable conflicts of interests to report.

The authors have no financial or proprietary interest in the subject matter or materials discussed in the manuscript.

Address for correspondence: $\quad$ David J Skarupa, MD

University of Florida

Department of Surgery

Division of Acute Care Surgery

Address: 655 West 8th Street

Jacksonville, FL 32209

E-mail: David.Skarupa@jax.ufl.edu

Tel: 904-244-3416 
Background: The optimal time to initiate chemical thromboprophylaxis (CTP) in patients who have undergone non-operative management $(\mathrm{NOM})$ of blunt solid organ injuries remains controversial. The aim of our study was to assess the impact of early initiation of CTP in patients with blunt abdominal solid organ injuries (SOI).

Methods: We performed a 2-year (2013-14) retrospective analysis of ACS-TQIP. We included all adult trauma patients (Age $\geq 18$ years) with blunt SOI who underwent NOM. Patients were stratified into 3 groups based on timing of CTP (early $\leq 48$-hours of injury, late $>48$-hours of injury and No Prophylaxis group). Our primary outcomes were rates of failure of NOM, pRBC transfusion, and mortality. Our secondary outcomes were the rate of venous thromboembolic (VTE) events (i.e. DVT and/or PE), and length of stay.

Results: A total of 36,187 patients met the inclusion criteria. Mean age was $49.5 \pm 19 \mathrm{y}$ and $36 \%$ of patients received CTP (Early: 37\% $(\mathrm{n}=4,819) v$ s. Late: $63 \%(\mathrm{n}=8,208))$. After controlling for confounders, patients receiving early CTP had lower rates of DVT $(\mathrm{p}=0.01)$ and PE $(\mathrm{p}=0.01)$ compared to the no prophylaxis and late CTP groups. There was no difference between the three groups regarding the post-prophylaxis pRBCs transfusions, failure of NOM, and mortality.

Conclusions: Our results suggest that in patients undergoing NOM of blunt abdominal SOI, early initiation of CTP should be considered. It is associated with decreased rates of DVT and $\mathrm{PE}$, with no significant difference in post prophylaxis $\mathrm{pRBCs}$ transfusion, failure of non-op management, and mortality. 
Level of Evidence: Level IV Therapeutic

Keywords: Chemical Thromboprophylaxis, Blunt Trauma, Solid Organs Injury, TQIP 


\section{Introduction}

Trauma patients are at increased risk of venous thromboembolic events (VTE) (1). Despite wide variations in the incidence of VTE in this population following different types of injuries (24), the overall incidence of VTE was reported in a systematic review to be around $12 \%$ in patients who received no thromboprophylaxis and $7 \%$ in those who received only mechanical thromboprophylaxis (5). Pulmonary embolism is also one of the significant causes of morbidity and mortality in the post-injury period (6). Even when chemical thromboprophylaxis (CTP) has been initiated, VTE can still be detected in one in six patients upon screening using venous duplex ultrasonography (7). The initiation of CTP in injured patients remains a challenging endeavor especially in patients with blunt solid organ injuries. The most common organs to be injured following blunt abdominal injury, are the spleen and liver followed by the kidney. The management of solid organ injuries underwent major strides over the past couple of decades. The majority of these injuries are now managed non-operatively or using minimally invasive techniques such as angioembolization as opposed to surgery especially when these patients are hemodynamically stable (8). One of the main reasons behind this is that the approach to nonoperative management requires adequate imaging modalities that were not available in the past. The advent of ultrasonography and computed tomography allowed clinicians to accurately evaluate solid organ injuries without the need for surgical exploration. (9)

There are often overlapping priorities in the management of patients with solid organ injuries. While hemostasis at the injury site takes precedence over other management considerations, these patients are at risk of venous thromboembolic events (deep vein thrombosis and/or pulmonary embolism), especially when they meet all elements of the Virchow triad (hypercoagulability, stasis, endothelial injury) (10). Venous thromboembolic events are prevalent 
in blunt solid organ injury patients and can be fatal. Thromboelastography (TEG) based studies have suggested that patients with blunt abdominal solid organ injuries eventually transition to a hypercoagulable state approximately 48 hours following trauma (11). The incidence of VTE complications is utilized as a quality metric in surgical care. The reduction of the overall burden of VTE is a major target by various quality improvement initiatives such as the American College of Surgeons Trauma Quality Improvement Program (ACS-TQIP) (12). The modalities recommended for VTE prevention include mechanical prophylaxis (sequential compression devices, early ambulation), and chemical prophylaxis (unfractionated heparin or low molecular weight heparin) $(13,14)$. The safety and efficacy of CTP in the setting of solid organ injuries are concerning for the prescribing clinician especially when considering the tradeoff between the risks of hemorrhage, failure of non-operative management $(15,16)$, and VTE events. The timing for initiation of CTP that optimizes these risks is also poorly defined (17). Despite this emphasis, no definitive guidelines exist as to when is the optimal time to start CTP in patients with a solid organ injury managed non-operatively. The aim of our study was to assess the safety and efficacy of early initiation of CTP in patients with blunt abdominal solid organ injuries that were managed non-operatively.

\section{$\underline{\text { Methods }}$}

We performed a 2-year (2013-2014) retrospective analysis of the American College of Surgeons Trauma Quality Improvement Program database. The ACS-TQIP is a well-known registry designed to improve the quality of trauma care using a risk-adjusted benchmarking methodology. As of 2018, more than 800 hospitals are participating in TQIP. Trained personnel abstract more than 100 patient and institutional variables. Although TQIP is administrated by the ACS, the analyses and conclusions presented here are solely performed by the authors (12). The 
ACS-TQIP only contains de-identified data and institutional review board approval was exempted by the University of Arizona.

\section{Study Population}

We included all adult trauma patients aged $\geq 18$ years with at least one blunt abdominal solid organ injury (SOI) [i.e. liver, spleen, or kidney] who underwent non-operative management. We excluded the patients who had severe head injuries (head-abbreviate injury scale score [h-AIS] $\geq 3$ ), spinal cord injuries (spine-abbreviate injury scale score $[\mathrm{s}-\mathrm{AIS}] \geq 2$ ), were dead on arrival, transferred from other institutions, or burned, as well as those that had missing data about CTP or had a penetrating mechanism of injury.

\section{Patient Stratification}

Thromboelastography based studies have suggested that patients with blunt abdominal solid organ injuries may transition to a hypercoagulable state within 48 hours of injury (11). Taking this into consideration, the patients were stratified into 3 groups based on their receipt of CTP: early CTP $\leq 48$-hours of injury, late CTP $>48$-hours of injury, and no CTP.

\section{Data Points:}

For each patient, we abstracted the following data points from the database: patient demographics (age, gender, and race); injury parameters [type and mechanism of injury, injury severity score (ISS), and each body region abbreviated injury scale score (AIS), type and grade of solid organ injuries], emergency department (ED) vital signs; operative intervention for their solid organ injuries, packed red blood cells (pRBCs) volume transfused, hospital and intensive care unit (ICU) length of stay (LOS), deep venous thrombosis (DVT), pulmonary embolism (PE), and inhospital mortality.

\section{Definitions:}




\section{Solid organ injuries:}

We used the International Classification of Diseases version 9 (ICD-9) diagnosis codes and Abbreviated Injury Scale (AIS) codes to identify the presence of a solid organ injury and determine its grade

\section{Non-operative management:}

We used the ICD-9 procedure codes to identify patients who underwent surgical management for their SOI. A patient was considered to have undergone non-operative management if no surgical procedure for the SOI was performed within 6-hours of presentation to the emergency department (ED).

\section{Chemothromboprophylaxis (CTP):}

Defined as the receipt of a prophylactic dose of either low molecular weight heparin (LMWH) or unfractionated heparin (UFH) during the hospital stay.

\section{Time to initiation of CTP:}

The time to initiation of CTP was defined as the time from ED presentation to receipt of CTP.

Early-CTP: Receipt of CTP within $\leq 48$ hours of presentation.

Late-CTP: Receipt of CTP after 48 hours of presentation.

A receiver operator characteristic (ROC) curve analysis was performed to determine the cutoff point for the timing of initiation of CTP that optimizes the sensitivity and specificity of VTE prediction.

\section{Failure of non-operative management:}

If the patient underwent any surgical procedure for their SOI after the initiation of CTP, this was defined as failure of non-operative management.

Post-prophylaxis $p R B C$ s transfusion: 
TQIP provides data regarding the timing of initiation of CTP and transfusion of pRBCs. Postprophylaxis $\mathrm{pRBCs}$ was used as a surrogate for bleeding after initiation of CTP.

Deep Venous Thrombosis (DVT): The diagnosis of DVT was confirmed by a venogram, ultrasound, or CT scan.

Pulmonary Embolism (PE): A patient was found to have a PE if the result of the V-Q scan indicated that the probability of a pulmonary embolism was high, or if a pulmonary angiogram or a CT angiogram was positive.

\section{Missing Data}

Missing data was treated as missing completely at random (MCAR). Multiple imputations were performed using a missing value analysis technique. This technique is used to reduce bias and increase the number of available cases. To impute the datasets, the original data set was analyzed for random missing data points using Little's missing completely at random (MCAR) test. Multiple imputations were performed using the Markov Chain Monte Carlo method.

\section{Outcome Measures}

Our primary outcome measures were rates of failure of non-operative management, $\mathrm{pRBC}$ transfusion, and mortality after initiation of CTP. Our secondary outcome measures were the rate of venous thromboembolic (VTE) events (i.e. DVT and/or PE), and length of stay (hospital and intensive care unit).

\section{Statistical Analysis}

Continuous parametric data were reported as a mean (with standard deviation), continuous nonparametric data as a median (with interquartile range), and categorical data as proportions. To analyze the differences between the groups on a univariate level, we used a chi-square test for categorical variables, the Mann-Whitney $U$ test for continuous nonparametric data, and the 
independent Student's t-test for continuous parametric data.

We controlled for confounding variables using multivariable logistic regression. First we assessed the association between each plausible predictor variable and the binary outcomes, on a univariate level. Variables with a p-value $<0.2$ on the univariate analysis were then included in multivariable logistic regression model. On the multivariable logistic regression analysis, variables were considered significant at $\mathrm{p}<0.05$. The model fit was assessed using the Hosmer-Lemeshow test. In the logistic regression model, the Hosmer-Lemeshow test exceeded 0.05 and the tolerance was greater than 0.1 for all independent variables with a variance inflation factor of less than 10.0. For our study, we considered $\mathrm{p}<0.05$ as statistically significant. Statistical Package for Social Sciences (SPSS, Version 24; SPSS, Inc., Armonk, NY) was used to perform all statistical analyses. Results:

We analyzed a total of 416,104 trauma patients over the study period. 74,233 patients had a solid organ injury, of which 36,187 (48.7\%) patients met the inclusion criteria and were included in our analysis. $64 \%(n=23,160)$ of the patients did not receive any CTP during their hospital course (No-CTP group) while 13,027 (36\%) received CTP with either LMWH or UFH. Among the patients who received CTP, CTP was started $\leq 48$ hours in 4,819 (37\%) patients (early-CTP group) while 8,208 (63\%) of the patients received CTP after 48 hours (late-CTP group). Figure 1 demonstrates the study population of our analysis. Based on a ROC curve analysis, the timing of VTE prophylaxis initiation cutoff point that maximizes both the sensitivity and specificity for VTE prediction was determined to be 45.175 hours (Appendix 1)

Overall, the mean age was $49.5 \pm 19 y, 67.9 \%$ were male and $71.4 \%$ were white. On admission, the majority of patients were hemodynamically stable as the overall mean systolic blood pressure in the emergency room was $127 \pm 23 \mathrm{~mm}$ of $\mathrm{Hg}$ and the overall mean heart rate 
was $91 \pm 20$ beats per minute. In addition, the majority of patients were neurologically preserved on presentation as the overall median GCS was 15 [14-15]. The demographics and injury parameters of our patient cohorts are summarized in Table 1. The three study groups were significantly different from each other in terms of patient demographics, $\mathrm{SBP}<90 \mathrm{~mm}$ of $\mathrm{Hg}$, injury parameters, type and grades of solid organ injuries. Patients in No-CTP and late CTP groups were more severely injured and more likely to be presented after an MVC compared to patients in the early-CTP group. There were significant differences regarding the type of CTP agent used. Use of UFH was more predominant in early-CTP compared to late CTP group ( $25 \%$ vs $20.4 \%, p=0.01)$.

In terms of concomitant injuries, the overall median head-AIS was in the mild range 2[13] and was not different across the three groups. The overall median abdominal-AIS was in the moderate to severe range 3[2-4]. Table 1. The liver was the most commonly injured solid organ (43.2\%) followed by the spleen (37.9\%) and the kidney (14\%). $4.8 \%$ of the patients had combined injuries of two or more solid abdominal organs. Compared to the patients who received early-CTP, patients who did not receive CTP and those who received late CTP were more likely to have highgrade solid organ injuries.

On univariate analysis, there was no difference between the early and late-CTP group regarding the rate of post-prophylaxis $\mathrm{pRBCs}$ transfusion $(\mathrm{p}=0.21)$, failure of $\mathrm{NOM}(\mathrm{p}=0.16)$ and mortality $(\mathrm{p}=0.33)$. On analysis of secondary outcomes, both the early and the late-CTP group had lower rates of DVT, PE, and combined DVT and PE compared to the no-CTP group. The lateCTP group had the highest hospital and ICU-LOS followed by the early-CTP group and the no-

\section{CTP group. Table 2}

On regression analysis after controlling for possible confounding variables, patients in the early and the late-CTP groups had lower odds of developing DVT or PE relative to those who did 
not receive CTP. The prophylactic effects were more pronounced in the early-CTP group vs the late-CTP group (For DVT= OR: 0.75 vs 0.84; For PE= OR: 0.85 vs 0.91). There was no difference between the three groups regarding the rate of combined DVT and PE. Additionally, there was no difference between the three groups regarding the adjusted odds ratio of failure of NOM or mortality. Table 3. In terms of the proportion of patients who received a pRBC transfusion following CTP, there was no difference between the early and the late-CTP group.

We performed a sub-analysis based on the type of CTP agent comparing the same outcomes in patients who received LMWH, UFH, or no CTP. On the multivariate regression analysis, patients who received either LMWH or UFH had lower adjusted odds of developing DVT and PE, compared to patients who did not receive CTP. On comparison of LMWH and UFH, there was no apparent difference regarding DVT or PE prevention. Additionally, we did not find any difference between the three groups regarding the risk of bleeding complications and failure of NOM Table 4. We performed a sub-analysis to evaluate the rates of failure of NOM and postprophylaxis transfusion stratifying our sample by the type of injured solid organ along with the injury grade. Upon restratification of the patients who had a single solid organ injury, 15,546 sustained liver injuries, 13,665 spleen injuries, and 5,071 kidney injuries. The rate of failure of NOM was significantly higher in the spleen $(5.3 \%)$ and the kidney group $(4.4 \%)$ relative to the liver group $(3.4 \%)(p=0.01)$. Relatively higher grades of SOI (grade $\geq \mathrm{IV})$ were associated with higher rates of failure of NOM in comparison to lower grades of SOI $(p=0.01)$. The rate of postprophylaxis $\mathrm{pRBC}$ transfusion followed the same trend and was significantly higher in the spleen $(1.8 \%)$ and the kidney group $(1.7 \%)$ relative to the liver group $(1.1 \%)(p=0.01)$. Table 5

We performed another sub-analysis sub-stratifying the early CTP group into: CTP $\leq 24-$ hours and 24-hours $<$ CTP $\leq 48$-hours. The two groups were similar in demographic 
characteristics, and overall injury severity. Patients in the 24 -hours $<\mathrm{CTP} \leq 48$-hours group were more likely to have sustained a splenic injury $(\mathrm{p}=0.03)$ of higher grade $(\geq \mathrm{IV})(\mathrm{p}=0.01)$, and were also more likely to have more than one SOI $(\mathrm{p}=0.04)$. Examining the study outcomes there was no apparent difference in rates of failure of $\mathrm{NOM}(\mathrm{p}=0.85)$, post-prophylaxis $\mathrm{pRBCs}$ transfusion $(\mathrm{p}=0.86$ ), or mortality ( $\mathrm{p}=0.95)$. (Appendix 2$)$. The two subgroups also did not differ in terms of hospital $(\mathrm{p}=0.63)$ or ICU LOS $(\mathrm{p}=0.31)$, and rates of VTE events. No further differences were detected on a multivariable level after adjusting for measurable baseline imbalances (Appendix 3).

\section{Discussion:}

Existing literature recommends the early initiation of CTP in trauma patients. However, the risk of bleeding and failure of NOM limits this practice in patients with SOI who undergo NOM. Our study shows that early initiation of CTP ( $\leq 48$ hours) in these patients might be effective and safe. In our analysis, patients who received early ( $\leq 48$ hours) or late ( $>48$ hours) CTP had lower odds of developing VTE complications compared to patients who did not receive CTP. There was no difference in the risk for developing bleeding complications, failure of NOM or mortality between the three groups.

Trauma patients are at high risk of developing VTE complications during their hospital stay. Direct injury to the endothelial lining of vessels and stasis secondary to bed rest are the main culprits of VTE (18). It is estimated that a significant proportion of trauma patients can develop DVT when prophylaxis is not initiated (5). The literature also reports that the risk VTE is tripled if CTP is delayed beyond 4 days of hospitalization (19). Early initiation of CTP in trauma patients is recommended by The American College of Chest Physician and the Eastern Association for the Surgery of Trauma $(13,14)$. However, patients with SOI who are managed non-operatively 
(NOM) are a unique challenge. Multiple studies have demonstrated the safety and efficacy of early initiation of CTP in spine trauma, pelvic fractures and even in severe TBI (20-24). However, the safety and efficacy of initiating early CTP in patients with solid abdominal organ injuries remain unclear.

In our analysis of the ACS-TQIP database we found that early and late CTP were associated with lower rates of VTE complications in patients with SOI following NOM. Early-CTP was associated with a more pronounced prophylactic effect compared to late CTP. A recent study from Switzerland by Khatsilouskaya et al. analyzed the safety and efficacy of CTP. In their analysis of 179 adult trauma patients with SOI with NOM, they did not find any difference between early, late or no-CTP group regarding the rate of VTE complications (16). Similarly, another study by Joseph et al. analyzed 145 trauma patients with SOI who underwent NOM and received CTP with LMWH (25). In their analysis, there was no difference between the early and late groups regarding the VTE complications. Their results are opposite to our analysis. This discrepancy can be explained by the small sample sizes of the above-mentioned studies. If a power analysis was performed based on the latest study on this topic i.e. (study by Khatsilouskaya et al), a sample size of 1010 patients (505 individual in each group i.e. early vs late CTP) are required to find a difference with $90 \%$ power and an alpha of $5 \%(16)$. We have overcome this limitation by including a bigger sample size from a large national database across the United States. Similar to our results, Khan et al. and Zeeshan et al. have shown that early initiation of CTP is associated with lower rates of VTE complications in patients with isolated spine trauma $(20,21)$. Another study by Byrne et al compared the effectiveness of early vs late CTP in patients with severe TBI and they concluded that initiation of CTP within 48 hours was significantly associated with lower risk of VTE complications (22). Jehan et al have reported similar results in patients with pelvic fractures who 
were managed non-operatively (24). Chapman et al. conducted a TEG-based assessment of hypercoagulability following blunt solid abdominal organ injuries. Based on the observed TEG parameters the study concluded that patients with SOI transition to a hypercoagulable state approximately 48 hours after injury and that pharmacological prophylaxis should be considered sometime during this time window. The results of this study also support the findings in our analysis. Trauma patients can still exhibit a hypercoagulable state even earlier than what was suggested based on the data and the existing literature (within 24 hours). However, the outcomes after starting CTP within 24-hours were no different than 24-hours $<$ CTP $\leq 48$-hours.

Bleeding and failure of NOM are among the feared complications of starting CTP in patients with SOI. Most of the current studies that assessed the safety of early vs late CTP did not find any difference between the two regarding the rates of bleeding complications or failure of $\operatorname{NOM}(16,25-27)$. However, the two biggest limitation for these studies were inadequate power and the lack of a control group (i.e. No-CTP). To overcome these limitations we compared the safety of early and late-CTP with a true control group (i.e. the No-CTP group with a bigger sample size). Compared to the no-CTP group, both the early and the late-CTP groups did not increase the risk of failure of NOM or mortality on univariate unadjusted or even on multivariate adjusted analysis. Additionally, there was no difference between early and late-CTP regarding the postprophylaxis pRBCs transfusion. Our results are consistent with previously published studies.

Several retrospective studies have suggested that LMWH may be superior to UFH for CTP in trauma patients $(28,29)$. We performed a sub-analysis based on the type of CTP agent to compare the efficacy and safety of LMWH with UFH. In our sub-analysis, we found that both LMWH and UFH are associated with lower odds of developing VTE complications compared to no-CTP. However, the odds of developing VTE were similar between LMWH and UFH. We 
cannot establish with certainty that LMWH is equivalent to UFH because of lack of data regarding the dosing of the two agents, the frequency of administration, along with information about asymptomatic screening. The results, however, are apparently in line with the existing literature which are better designed to evaluate this comparison. Olson et al. conducted a randomized noninferiority trial comparing UFH dosed every 8 hours and standard LMWH dosed every 12 hours for VTE prophylaxis (30). UFH was non-inferior when compared to LMWH for VTE prophylaxis. Arnold et al highlighted that the use of UFH may be associated with a significant pharmaceutical cost advantage (20 fold lower) relative to LMWH in a prospective observational study performed in 2010 (31). The cost of LWMH relative to UFH has changed during the past decade and the cost advantage reported may no longer exist. LMWH is also dosed less frequently in comparison to UFH for VTE prophylaxis and this influences pharmaceutical costs. This was also overlooked in earlier studies which compared the two agents. Geerts et al. found LMWH given twice daily to be more effective than UFH given twice daily (32). In this way, patients in the UFH group received sub-prophylactic doses knowing that the recommended UFH dose for effective VTE prophylaxis is given three times daily (33) and this limits the validity of their conclusion. Furthermore, Zeeshan et al in their analysis of patients with operative spine trauma concluded that there was no difference between LMWH and UFH regarding prevention of VTE complications (20). On sub-analysis by organ, the results signify that the potential for failure of NOM and subsequent post-prophylaxis pRBC transfusion varies significantly depending on the type of injured solid organ. The spleen and the kidney were more likely to show delayed bleeding relative to the liver following injury. This risk is also augmented in the setting of higher grades of SOI (grade $\geq$ IV) relative to grades I, II, and III. This could be attributed to differences in the rate of healing and the injury burden. The 
type of solid organ injury along with the grade therefore should play an important role in the safety and efficacy considerations prior to initiating CTP.

Our study is not without limitations. Due to the retrospective nature of the study, we could not account for certain unmeasured confounding factors such as mechanical thromboprophylaxis, missed CTP doses, dosage and frequency of LMWH and UFH. Additionally, TQIP does not collect data on serial ultrasounds or screening for asymptomatic DVT. It also does not contain any center specific data. In this way we could not determine the surveillance practices for DVT at participating institutions that might have imparted a surveillance bias in our analysis. In addition, pulmonary emboli discovered on chest imaging may be de novo pulmonary thrombosis associated with a contusion or infection and we were not able to determine how many of these pulmonary emboli had a contemporary DVT. We used mortality and post-prophylaxis pRBCs transfusion as surrogate markers of bleeding complications, and we could not ascertain the cause of the transfusion, however, this method has been previously used in trauma research (20, 34-36). Furthermore, the conclusion of the sub-analysis comparing the efficacy and safety of LMWH versus UFH may not be definite in our analysis as TQIP does not have data regarding the doses and frequency of the CTP agents and these data points are needed for a definite comparison of the two agents. Despite these limitations, our study is unique. It has a large sample size from a multiinstitutional national database across the United States. To have a homogenous patient population, we excluded patients with severe head and spine injuries, those that were dead on arrival, transferred from other institutions, or burned, as well as those that had missing data about CTP or had a penetrating mechanism of injury. Our study provides evidence to help clinicians better define the timing for initiation of CTP in patients who undergo non-operative management for blunt SOI, especially since there is a paucity of data and lack of unified and definitive guidelines 


\section{Conclusion:}

In patients undergoing NOM of SOI, early CTP is associated with reduced rates of DVT and PE without increasing the risk of failure of NOM, bleeding complications, or mortality. Outcomes were not different when CTP was started within 24-hours compared to when CTP was started within 48-hours. Chemical thromboprophylaxis should be considered within 48 hours of presentation in patients with blunt abdominal solid organ injuries managed non-operatively. 


\section{Author contribution:}

DS, KH, MZ, BJ FM, ZH, and LG: Designed this study

DS, KH, MZ, BJ, MH, AN, and NK: Searched the literature

DS, KH, MZ, BJ, MH, AN, and LG: Collected the data

DS, KH, MZ, BJ, FM, ZH, and NK: Analyzed the data

All authors participated in data interpretation and manuscript preparation.

\section{Acknowledgements:}

None

\section{Conflict of interest:}

There are no identifiable conflicts of interests to report.

\section{Funding:}

This project was not funded 


\section{$\underline{\text { References: }}$}

1. Paffrath T, Wafaisade A, Lefering R, Simanski C, Bouillon B, Spanholtz T, Wutzler S, Maegele M, Trauma Registry of DGU. Venous thromboembolism after severe trauma: incidence, risk factors and outcome. Injury. 2010;41(1):97-101.

2. Platzer P, Thalhammer G, Jaindl M, Obradovic A, Benesch T, Vecsei V, Gaebler C. Thromboembolic complications after spinal surgery in trauma patients. Acta Orthop. 2006;77(5):755-60.

3. Denson K, Morgan D, Cunningham R, Nigliazzo A, Brackett D, Lane M, Smith B, Albrecht R. Incidence of venous thromboembolism in patients with traumatic brain injury. Am $J$ Surg. 2007;193(3):380-4.

4. Reiff DA, Haricharan RN, Bullington NM, Griffin RL, McGwin Jr G, Rue Iii LW. Traumatic brain injury is associated with the development of deep vein thrombosis independent of pharmacological prophylaxis. J Trauma Acute Care Surg. 2009;66(5):1436-40.

5. Barrera LM, Perel P, Ker K, Cirocchi R, Farinella E, Uribe CHM. Thromboprophylaxis for trauma patients. Cochrane Database Syst Rev. 2013(3).

6. Toker S, Hak DJ, Morgan SJ. Deep vein thrombosis prophylaxis in trauma patients. Thrombosis. 2011;2011.

7. Hill SL, Berry RE, Ruiz AJ. Deep venous thrombosis in the trauma patient. Am Surg. 1994;60(6):405-8.

8. Cimbanassi S, Chiara O, Leppaniemi A, Henry S, Scalea TM, Shanmuganathan K, Biffl W, Catena F, Ansaloni L, Tugnoli G. Nonoperative management of abdominal solid-organ injuries following blunt trauma in adults: Results from an International Consensus Conference. J Trauma Acute Care Surg. 2018;84(3):517-31. 
9. Leppäniemi A. Nonoperative management of solid abdominal organ injuries: From past to present. Scand J Surg. 2019:1457496919833220.

10. Knudson MM, Ikossi DG, Khaw L, Morabito D, Speetzen LS. Thromboembolism after trauma: an analysis of 1602 episodes from the American College of Surgeons National Trauma Data Bank. Ann Surg. 2004;240(3):490.

11. Chapman BC, Moore EE, Barnett C, Stovall RT, Biffl WL, Burlew CC, Bensard DD, Jurkovich GJ, Pieracci FM. Hypercoagulability following blunt solid abdominal organ injury: when to initiate anticoagulation. Am J Surg. 2013;206(6):917-23.

12. Surgeons ACo. Trauma Quality Improvement Program.

13. Kearon C, Akl EA, Comerota AJ, Prandoni P, Bounameaux H, Goldhaber SZ, Nelson ME, Wells PS, Gould MK, Dentali F. Antithrombotic therapy for VTE disease: antithrombotic therapy and prevention of thrombosis: American College of Chest Physicians evidence-based clinical practice guidelines. Chest. 2012;141(2):e419S-e96S.

14. Rogers FB, Cipolle MD, Velmahos G, Rozycki G, Luchette FA. Practice management guidelines for the prevention of venous thromboembolism in trauma patients: the EAST practice management guidelines work group. J Trauma Acute Care Surg. 2002;53(1):142-64.

15. Norwood SH, McAuley CE, Berne JD, Vallina VL, Kerns DB, Grahm TW, McLarty JW. A potentially expanded role for enoxaparin in preventing venous thromboembolism in high risk blunt trauma patients. J Am Coll Surg. 2001;192(2):161-7.

16. Khatsilouskaya T, Haltmeier T, Cathomas M, Eberle B, Candinas D, Schnüriger B. Thromboembolic prophylaxis with heparin in patients with blunt solid organ injuries undergoing non-operative treatment. World J Surg. 2017;41(5):1193-200. 
17. Ferguson C, Lewin J. BET 2: Is early chemical thromboprophylaxis safe in patients with blunt trauma solid organ injury (SOI) undergoing non-operative management (NOM)? Emerg Med J. 2018;35(2):127-9.

18. Geerts WH, Code KI, Jay RM, Chen E, Szalai JP. A prospective study of venous thromboembolism after major trauma. $N$ Eng J Med. 1994;331(24):1601-6.

19. Nathens AB, McMurray MK, Cuschieri J, Durr EA, Moore EE, Bankey PE, Freeman B, Harbrecht BG, Johnson JL, Minei JP, et al. The practice of venous thromboembolism prophylaxis in the major trauma patient. J Trauma. 2007;62(3):557-62; discussion 62-3.

20. Zeeshan M, Khan M, O’Keeffe T, Pollack N, Hamidi M, Kulvatunyou N, Sakran JV, Gries L, Joseph B. Optimal timing of initiation of thromboprophylaxis in spine trauma managed operatively: A nationwide propensity-matched analysis of trauma quality improvement program. J Trauma Acute Care Surg. 2018;85(2):387-92.

21. Khan M, Jehan F, O'Keeffe T, Hamidi M, Truitt M, Zeeshan M, Gries L, Tang A, Joseph B. Optimal Timing of Initiation of Thromboprophylaxis after Nonoperative Blunt Spinal Trauma: A Propensity-Matched Analysis. J Am Coll Surg. 2018;226(5):760-8.

22. Byrne JP, Mason SA, Gomez D, Hoeft C, Subacius H, Xiong W, Neal M, Pirouzmand F, Nathens AB. Timing of pharmacologic venous thromboembolism prophylaxis in severe traumatic brain injury: a propensity-matched cohort study. $J$ Am Coll Surg. 2016;223(4):621-31. e5.

23. Meyer D, Joseph B, Pandit V, Kulvatunyou N, Khalil M, O'Keeffe T, Tang AL, Vercruysse GA, Friese RS, Rhee PM. Early use of venous thromboembolic prophylaxis in traumatic brain injury: a safe practice. J Am Coll Surg. 2014;219(3):S69. 
24. Jehan F, O'Keeffe T, Khan M, Chi A, Tang A, Kulvatunyou N, Gries L, Joseph B. Early thromboprophylaxis with low-molecular-weight heparin is safe in patients with pelvic fracture managed nonoperatively. $J$ Surg Res. 2017;219:360-5.

25. Joseph B, Pandit V, Harrison C, Lubin D, Kulvatunyou N, Zangbar B, Tang A, O'Keeffe T, Green DJ, Gries L. Early thromboembolic prophylaxis in patients with blunt solid abdominal organ injuries undergoing nonoperative management: is it safe? Am J Surg. 2015;209(1):194-8.

26. Eberle BM, Schnüriger B, Inaba K, Cestero R, Kobayashi L, Barmparas G, Oliver M, Demetriades D. Thromboembolic prophylaxis with low-molecular-weight heparin in patients with blunt solid abdominal organ injuries undergoing nonoperative management: current practice and outcomes. J Trauma Acute Care Surg. 2011;70(1):141-7.

27. Kwok AM, Davis JW, Dirks RC, Wolfe MM, Kaups KL. Time is now: venous thromboembolism prophylaxis in blunt splenic injury. Am J Surg. 2016;212(6):1231-6.

28. Beere HM, Wolf BB, Cain K, Mosser DD, Mahboubi A, Kuwana T, Tailor P, Morimoto RI, Cohen GM, Green DR. Heat-shock protein 70 inhibits apoptosis by preventing recruitment of procaspase-9 to the Apaf-1 apoptosome. Nat Cell Biol. 2000;2(8):469.

29. Benjamin E, Recinos G, Aiolfi A, Inaba K, Demetriades D. Pharmacological thromboembolic prophylaxis in traumatic brain injuries: low molecular weight heparin is superior to unfractionated heparin. Ann Surg. 2017;266(3):463-9.

30. Olson EJ, Bandle J, Calvo RY, Shackford SR, Dunne CE, Van Gent J-M, Zander AL, Sikand H, Bongiovanni MS, Sise MJ. Heparin versus enoxaparin for prevention of venous thromboembolism after trauma: A randomized noninferiority trial. J Trauma Acute Care Surg. 2015;79(6):961-9. 
31. Arnold JD, Dart BW, Barker DE, Maxwell RA, Burkholder HC, Mejia VA, Smith PW, Longley JM. Gold Medal Forum Winner. Unfractionated heparin three times a day versus enoxaparin in the prevention of deep vein thrombosis in trauma patients. Am Surg. 2010;76(6):56370.

32. Geerts WH, Jay RM, Code KI, Chen E, Szalai JP, Saibil EA, Hamilton PA. A comparison of low-dose heparin with low-molecular-weight heparin as prophylaxis against venous thromboembolism after major trauma. $N$ Engl J Med. 1996;335(10):701-7.

33. Kakkar VV. Low-Dose Heparin in the Prevention of Venous Thromboembolism Rationale and Results. In: Bradshaw RA, Wessler S, editors. Heparin: Structure, Function, and Clinical Implications. Boston, MA: Springer US; 1975. p. 323-40.

34. Feeney JM, Santone E, DiFiori M, Kis L, Jayaraman V, Montgomery SC. Compared to warfarin, direct oral anticoagulants are associated with lower mortality in patients with blunt traumatic intracranial hemorrhage: a TQIP study. J Trauma Acute Care Surg. 2016;81(5):843-8.

35. Matsushima K, Piccinini A, Schellenberg M, Cheng V, Heindel P, Strumwasser A, Benjamin E, Inaba K, Demetriades D. Effect of door-to-angioembolization time on mortality in pelvic fracture: Every hour of delay counts. J Trauma Acute Care Surg. 2018;84(5):685-92.

36. Jehan F, Aziz H, O'Keeffe T, Khan M, Hamidi M, Zeeshan M, Kulvatunyou N, Joseph B. The role of four-factor prothrombin complex concentrate in coagulopathy of trauma: a propensity matched analysis. $J$ Trauma Acute Care Surg. 2018;85(1):18-24. 
Figure legends

Figure 1: Study population 


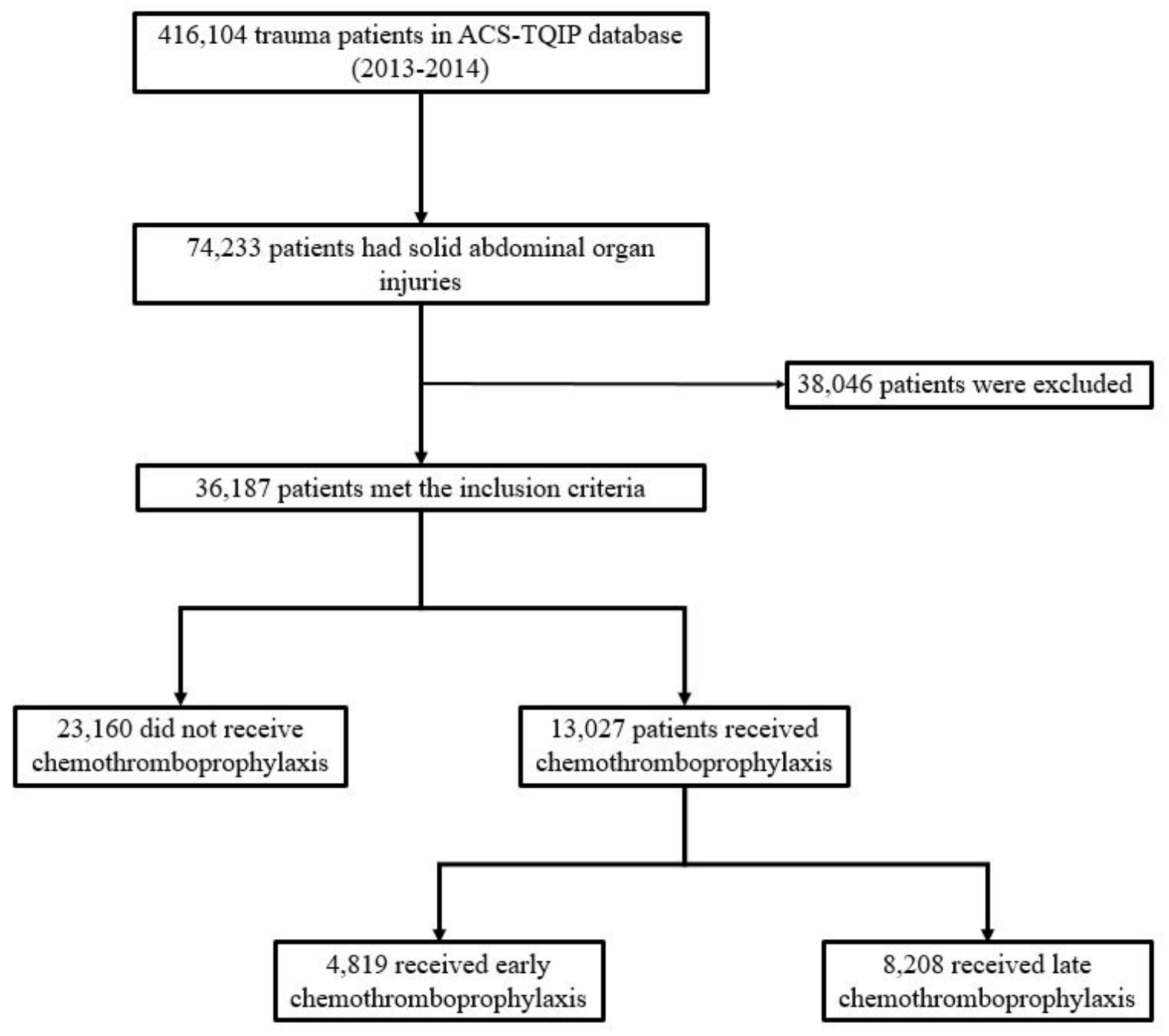




\begin{tabular}{|c|c|c|c|c|}
\hline Characteristics & $\begin{array}{c}\text { No CTP } \\
(n=23,160)\end{array}$ & $\begin{array}{c}\text { Early CTP } \\
(n=4,819)\end{array}$ & $\begin{array}{l}\text { Late CTP } \\
(n=8,208)\end{array}$ & P-value \\
\hline Age, years, mean $\pm \mathrm{SD}$ & $50.6 \pm 18$ & $49.2 \pm 19$ & $49.6 \pm 20$ & 0.21 \\
\hline Male, \% (n) & $68.9 \%(15957)$ & $66.5 \%(3205)$ & $66.1 \%(5425)$ & 0.03 \\
\hline Whites, \% (n) & $72.3 \%(16745)$ & $70.5 \%(3397)$ & $69.4 \%(5696)$ & 0.03 \\
\hline Hispanics, \% (n) & $13.3 \%(3080)$ & $10.2 \%(492)$ & $10.8 \%(886)$ & 0.04 \\
\hline $\mathrm{BMI}$, mean $\pm \mathrm{SD}$ & $25.3 \pm 7.6$ & $25.7 \pm 8.4$ & $25.0 \pm 8.2$ & 0.26 \\
\hline \multicolumn{5}{|l|}{ Vital parameters } \\
\hline ED SBP<90mmHg, \% (n) & $7.7 \%(1783)$ & $4.7 \%(226)$ & $8.2 \%(673)$ & 0.01 \\
\hline \multicolumn{5}{|l|}{ Injury Parameters } \\
\hline ISS, median [IQR] & $22[16-29]$ & $20[17-27]$ & $26[18-30]$ & 0.04 \\
\hline Abdominal AIS $>3, \%$ (n) & $20.2 \%(4678)$ & $18.6 \%(896)$ & $24.3 \%(1995)$ & 0.01 \\
\hline \multicolumn{5}{|l|}{ Mechanism of Injury,\% (n) } \\
\hline MVC & $63.9 \%(14799)$ & $61.4 \%(2959)$ & $64.1 \%(5261)$ & 0.03 \\
\hline Others & $36.1 \%(8361)$ & $38.6 \%(1860)$ & $35.9 \%(2947)$ & \\
\hline \multicolumn{5}{|c|}{ Abdominal Solid Organs Injured, \% (n) } \\
\hline Liver, & $40.2 \%(9310)$ & $46.1 \%(2222)$ & $48.9 \%(4014)$ & 0.01 \\
\hline Grade $\geq \mathrm{IV}$ & $16.3 \%(3775)$ & $14.8 \%(713)$ & $20.6 \%(1691)$ & 0.01 \\
\hline Spleen, & $39.4 \%(9125)$ & $36.3 \%(1749)$ & $34 \%(2791)$ & 0.01 \\
\hline Grade $\geq \mathrm{IV}$, & $17.5 \%(4053)$ & $16.2 \%(781)$ & $19.4 \%(1592)$ & 0.01 \\
\hline Kidney, & $15.2 \%(3520)$ & $13.1 \%(631)$ & $11.2 \%(919)$ & 0.02 \\
\hline Grade $\geq \mathbf{I V}$ & $17.2 \%(3984)$ & $13.7 \%(660)$ & $19.4 \%(1592)$ & 0.01 \\
\hline Multiple Organs Injured & $4.9 \%(1135)$ & $4.5 \%(217)$ & $5.9 \%(484)$ & 0.03 \\
\hline \multicolumn{5}{|l|}{ CTP agent, \% (n) } \\
\hline UFH & N/A & $25 \%(1205)$ & $20.4 \%(1674)$ & 0.01 \\
\hline LMWH & N/A & $75 \%(3614)$ & $79.6 \%(6534)$ & \\
\hline
\end{tabular}

$\overline{\mathrm{CTP}}=$ Chemothromboprophylaxis, SD = Standard Deviation, BMI = Body Mass Index, GCS = Glasgow Coma Scale, ED = Emergency Department, SBP = Systolic Blood Pressure, HR = Heart Rate, ISS = Injury Severity Score, AIS = Abbreviated Injury Scale, MVC = Motor Vehicle Collision, UFH = Unfractionated Heparin, LMWH = Low Molecular Weight Heparin. 
Table 2. Primary and Secondary Outcome Measures

\begin{tabular}{lcccr}
\hline Outcomes & $\begin{array}{c}\text { No CTP } \\
(\mathbf{n = 2 3 , 1 6 0 )}\end{array}$ & $\begin{array}{c}\text { Early CTP } \\
(\mathbf{n}=\mathbf{4 , 8 1 9})\end{array}$ & $\begin{array}{c}\text { Late CTP } \\
(\mathbf{n}=\mathbf{8 , 2 0 8})\end{array}$ & $P$-valu \\
\hline Primary & & & & \\
$\quad$ Failure of NOM, \% (n) & $4 \%(926)$ & $4.6 \%(221)$ & $4.2 \%(344)$ & 0.16 \\
$\quad \begin{array}{l}\text { Post-prophylaxis pRBCs } \\
\text { transfusions received, \% (n) }\end{array}$ & - & $3.9 \%(188)$ & $3.8 \%(312)$ & 0.21 \\
$\quad$ Mortality, \% (n) & $2.4 \%(556)$ & $2.0 \%(96)$ & $2.3 \%(189)$ & 0.33
\end{tabular}

\section{Secondary}

Hospital LOS, d, median[IQR]

5 [3-7]

6 [4-12]

8 [6-18]

0.02

ICU LOS, d, median[IQR]

$2[1-4]$

$3[2-6]$

$4[3-6]$

0.03

DVT, \% (n)

$5.4 \%(1250) \quad 1.9 \%(91)$

$4.1 \%(336)$

0.01

PE, \% (n)

$2.9 \%(671) \quad 1.0 \%(48)$

$1.8 \%(147)$

0.01

DVT and PE, \% (n)

$1.1 \%(255) \quad 0.1 \%(5)$

$0.3 \%(25)$

0.01

CTP $=$ Chemothromboprophylaxis, DVT $=$ Deep Venous Thrombosis, $\mathrm{PE}=$ Pulmonary Embolism, $\mathrm{pRBCs}=$ packed red blood cells, $\mathrm{LOS}=$ Length of Stay, $\mathrm{d}=$ days, IQR = interquartile range, ICU = Intensive Care Unit, NOM = Non-operative management, 
Table 3. Multivariate Regression Analysis

\begin{tabular}{|c|c|c|c|}
\hline Outcomes & OR & 95\% Confidence Interval & P-value \\
\hline \multicolumn{4}{|c|}{ Deep Venous Thrombosis } \\
\hline No-CTP & 1 & Reference & -- \\
\hline Early CTP & 0.75 & $0.69-0.78$ & 0.01 \\
\hline Late CTP & 0.84 & $0.81-0.89$ & 0.01 \\
\hline \multicolumn{4}{|c|}{ Pulmonary Embolism } \\
\hline No-CTP & 1 & Reference & -- \\
\hline Early CTP & 0.85 & $0.71-0.87$ & 0.03 \\
\hline Late CTP & 0.91 & $0.89-0.97$ & 0.04 \\
\hline \multicolumn{4}{|c|}{ Combined Deep Venous Thrombosis and Pulmonary Embolism } \\
\hline No-CTP & 1 & Reference & -- \\
\hline Early CTP & 0.92 & $0.86-1.06$ & 0.10 \\
\hline Late CTP & 0.96 & $0.89-1.10$ & 0.19 \\
\hline \multicolumn{4}{|c|}{ Post-Prophylaxis pRBCs Transfusion } \\
\hline No-CTP & -- & -- & -- \\
\hline Early CTP & 1.05 & $0.94-2.12$ & 0.35 \\
\hline Late CTP & 1 & Reference & -- \\
\hline \multicolumn{4}{|c|}{ Failure of non-operative management } \\
\hline No-CTP & 1 & Reference & -- \\
\hline Early CTP & 1.05 & $0.89-2.11$ & 0.12 \\
\hline Late CTP & 0.96 & $0.91-2.09$ & 0.30 \\
\hline \multicolumn{4}{|l|}{ Mortality } \\
\hline No-CTP & 1 & Reference & -- \\
\hline Early CTP & 1.04 & $0.91-2.28$ & 0.26 \\
\hline Late CTP & 0.99 & $0.90-1.67$ & 0.37 \\
\hline
\end{tabular}

$\mathrm{CTP}=$ chemothromboprophylaxis, $\mathrm{pRBCs}=$ packed red blood cells 
Table 4. Sub-analysis based on the type of CTP agent

\begin{tabular}{|c|c|c|c|}
\hline Outcomes & OR & 95\% Confidence Interval & P-value \\
\hline \multicolumn{4}{|c|}{ Deep Venous Thrombosis } \\
\hline No-CTP & 1 & Reference & -- \\
\hline LMWH & 0.81 & $0.72-0.89$ & 0.01 \\
\hline UFH & 0.86 & $0.82-0.93$ & 0.01 \\
\hline \multicolumn{4}{|c|}{ Pulmonary Embolism } \\
\hline No-CTP & 1 & Reference & -- \\
\hline LMWH & 0.82 & $0.77-0.89$ & 0.03 \\
\hline UFH & 0.90 & $0.85-0.98$ & 0.04 \\
\hline \multicolumn{4}{|c|}{ Post-Prophylaxis pRBCs Transfusion } \\
\hline No-CTP & -- & -- & -- \\
\hline LMWH & 0.99 & $0.91-1.82$ & 0.26 \\
\hline UFH & 1 & Reference & -- \\
\hline \multicolumn{4}{|c|}{ Failure of non-operative management } \\
\hline No-CTP & 1 & Reference & -- \\
\hline LMWH & 1.09 & $0.93-1.63$ & 0.15 \\
\hline UFH & 1.10 & $0.91-1.28$ & 0.67 \\
\hline \multicolumn{4}{|l|}{ Mortality } \\
\hline No-CTP & 1 & Reference & -- \\
\hline LMWH & 0.97 & $0.94-2.34$ & 0.64 \\
\hline UFH & 1.06 & $0.92-2.51$ & 0.79 \\
\hline
\end{tabular}




\section{Table 5. Sub-analysis by Organ and Injury Grade}

\begin{tabular}{|c|c|c|c|c|c|c|c|}
\hline \multirow{2}{*}{$\begin{array}{l}\text { Characteristics } \\
\text { Injury Grade }\end{array}$} & \multicolumn{2}{|c|}{$\begin{array}{c}\text { Liver } \\
(n=15546)\end{array}$} & \multicolumn{2}{|c|}{$\begin{array}{c}\text { Spleen } \\
(n=13665)\end{array}$} & \multicolumn{2}{|c|}{$\begin{array}{c}\text { Kidney } \\
(n=5071)\end{array}$} & \multirow[t]{2}{*}{ P-value } \\
\hline & I-III & $\geq \mathbf{I V}$ & I-III & $\geq \mathbf{I V}$ & I-III & $\geq \mathbf{I V}$ & \\
\hline Failure of NOM, \% (n) & $1.2 \%(187)$ & $2.2 \%(342)$ & $1.6 \%(219)$ & $3.7 \%(506)$ & $1.6 \%(81)$ & $2.8 \%(142)$ & 0.01 \\
\hline $\begin{array}{l}\text { Post-prophylaxis pRBCs } \\
\text { transfusions received, \% (n) }\end{array}$ & $0.4 \%(62)$ & $0.7 \%(109)$ & $0.6 \%(82)$ & $1.2 \%(164)$ & $0.6 \%(30)$ & $1.1 \%(56)$ & 0.01 \\
\hline
\end{tabular}

NOM=Non-operative management; $\mathrm{pRBC}=$ packed red blood cells 